\title{
Bronchopleural Fistula
}

National Cancer Institute

\section{Source}

National Cancer Institute. Bronchopleural Fistula. NCI Thesaurus. Code C80694.

An abnormal communication between a bronchus and the pleural cavity. 